\title{
Mapeamento e gestão de resíduos em uma indústria moveleira da Serra Gaúcha, Estado do Rio Grande do Sul, Brasil
}

\author{
Eléia Righi' ${ }^{1}$, Carla Variani², Isabel Plínia Andrade Dias ${ }^{2}$
}

1Universidade Estadual do Rio Grande do Sul. Av. Júlio de Castilhos, 3947. Bairro Cinquentenário. Caxias do Sul-RS, Brasil (CEP 95010-005). E-mail: eleiarighi@uergs.edu.br.

${ }^{2}$ Curso de Bacharelado em Ciências e Tecnologia de Alimentos. Unidade Universitária Caxias do Sul. Universidade Estadual do Rio Grande do Sul. Av. Júlio de Castilhos, 3947. Bairro Cinquentenário. Caxias do Sul-RS, Brasil (CEP 95010-005).

Resumo. Este trabalho objetivou verificar todos os processos de gestão de resíduos, desenvolvido em uma indústria moveleira, localizada no Município de Flores da Cunha, no Estado do Rio Grande do Sul, Brasil. Com a finalidade de observar todos os processos que os resíduos percorrem, de quais setores eles se originam, qual sua destinação final, e se estão realizando conforme a Lei no 12.305/2010, e o Sistema de Gestão Ambiental, além da ABN NBR 10004:2004. Verificou-se que a geração de resíduos é grande, e 100\% são destinados corretamente, conforme a legislação. A indústria investiu em tratamentos específicos na busca de minimizar impactos no ambiente. Assim, concluímos que o desenvolvimento do presente estudo permitiu uma análise consistentes sobre as etapas dos processos de gerenciamento de resíduos nos setores.

Palavras-chave: Sustentabilidade; Gestão de Resíduos Sólidos; Políticas públicas ambientais.

Abstract. Mapping and waste management in a furniture industry of Serra Gaúcha, Rio Grande do Sul State, Brazil. This work aimed to verify all waste management processes, developed in a furniture industry, located in the Municipality of Flores da Cunha, in Rio Grande do Sul, Brazil. In order to observe all the processes that the waste goes through, of which sectors they are and are being carried out in accordance with Law No. 12,305/2010, and the Environmental Management System, in addition to the ABNT NBR 10004:2004. We verified that the generation of waste is large, and $100 \%$ are destined correctly, according to the legislation. The industry has invested in specific treatments in the quest to minimize impacts on the environment. Thus, we conclude that the development of this study allowed a consistent analysis of the stages of the waste management processes in the sectors.
Recebido:

16/09/2018

Aceito:

28/11/2018

Publicado:

$31 / 12 / 2018$

Acesso aberto

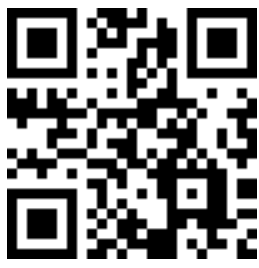

ORCID

(1) 0000-0002-2766-8719 Eléia Righi

(1) 0000-0002-0792-1051 Carla Variani

(1) 0000-0002-1239-7020 Isabel Plínia Andrade Dias 
Keywords: Sustainability; Solid waste management;
Environmental public policy.

\section{Introdução}

A fabricação de móveis, em especial, os produzidos com madeira é uma das mais tradicionais atividades que se insere na indústria de transformação. Ademais o relatório do IEMI (2015), destaca que a indústria de móveis se caracteriza de forma peculiar, pois integra uma diversidade de processos de produção, aliada ao uso de diferentes tipos de matérias primas, gerando por sua vez uma gama de produtos finais.

Segundo Guéron e Garrido (2004), a indústria de madeira e móveis deve ser entendida como parte do setor de base florestal, que compreende ainda o segmento de papel e celulose e de lenha e carvão vegetal. A partir de um primeiro processo de transformação industrial, a indústria da madeira pode ser desdobrada em indústrias de serrados, painéis de madeira reconstituída, remanufaturados e a indústria de móveis. Esta última compreende um segundo processo de beneficiamento, originando produtos com maior valor agregado.

Apesar do fato de a madeira ser o material mais abundante biodegradável e renovável disponível, existe inúmeras razões para maximizar a sua utilização, onde há preocupações econômicas, sociais e principalmente com as mudanças climáticas e a emissão de gases de efeito estufa, bem como a ameaça as florestas devido a efeitos adversos do clima, podem ser eficazmente combatidos pelo aumento da utilização de resíduos de madeira (Daian e Ozarska, 2009).

Brand e Hassegawa (2005), num

trabalho para determinação da quantidade de resíduos madeiráveis gerados nas indústrias madeireiras em um raio de $150 \mathrm{~km}$ do Município de Otacílio Costa, verificaram que os resíduos gerados em maior quantidade pelas empresas da região são cavaco com casca, resíduos de lâminas, serragem e rolo-resto. As atividades com maior representação na produção de resíduos são as serrarias e laminadoras, que se constituem em indústrias de transformação primária da madeira, e que produzem em torno de $80 \%$ do volume total de resíduos.

Com relação ao destino ou aproveitamento dos resíduos gerados, Schneider et al. (2004) verificaram que uma parcela expressiva dos resíduos de madeira e derivados das indústrias do polo moveleiro da Serra Gaúcha, em 2004, igual a 6,7\%, ainda é descartada para queima, sem aproveitamento. Outra parcela, que corresponde a $8,3 \%$ dos resíduos gerados, é doada, não agregando valor nenhum nesta operação. Lima (2005), em um trabalho com o objetivo de verificar o desempenho ambiental das indústrias de móveis de madeira situadas no Polo Moveleiro de Arapongas, no stad do Paraná, verificou que, de todos os resíduos gerados, os resíduos em maior quantidade são os resíduos de madeira, respondendo por $85 \%$ dos resíduos totais gerados. Desses resíduos, como pedaços, pó e cepilho, boa parte são destinados para confecção de briquetes. 0 autor comenta que no geral $82 \%$ das empresas pesquisadas aproveitam algum tipo de resíduo no próprio processo, 53\% vendem parte dos resíduos e apenas 6\% os queimam.

O manejo adequado dos resíduos é uma importante estratégia de preservação do meio ambiente, assim como de promoção e proteção da saúde. Uma vez acondicionados em aterros, os resíduos sólidos podem comprometer a qualidade do solo, da água e do ar, por serem fontes de compostos orgânicos voláteis, pesticidas, solventes e metais pesados, entre outros (Gouveia, 2012).

Segundo Nahuz (2001), estima-se que menos de $5 \%$ das empresas do setor 
moveleiro tem programas de conservação do meio ambiente e não existe plano de gestão integrada de resíduos no setor. Além da madeira ser a principal fonte de matéria-prima, a indústria de móveis também utiliza materiais como: plásticos, papelão, aço, vidro, ferro, materiais têxteis, tinta, cola, verniz, etc. A variedade e a origem distinta dos materiais utilizados no processo industrial geram resíduos sólidos, emissões atmosféricas e efluentes líquidas.

Os resíduos sólidos se tornaram um dos problemas mais preocupantes da sociedade humana nos últimos anos, uma vez que o seu ritmo de produção, bem como sua capacidade de deposição é cada vez mais limitado, não só pela escassez de espaço físico como também da legislação que se torna cada vez mais rígida no que tange a questão ambiental (Wright, 2004).

Assim, esse trabalho objetivou verificar todos os processos de gestão de resíduos, desenvolvido em uma empresa moveleira, localizada no município de Flores da Cunha, no Rio Grande do Sul. Com a finalidade de observar todos os processos que os resíduos percorrem, de quais setores eles se originam, qual sua destinação final, e se estão realizando conforme a Lei no 12.305/2010 (Brasil, 2010) e o Sistema de Gestão Ambiental, além da ABNT NBR 10004:20004 (ABNT, 2004).

\section{Material e método}

\section{Local de estudo}

Contornado pela natureza exuberante, o Município de Flores da Cunha, que é chamada carinhosamente de Terra do Galo, está localizado na Serra
Gaúcha, a cerca de $150 \mathrm{~km}$ da capital Porto Alegre e a $710 \mathrm{~m}$ de altitude acima do nível do mar (Figura 1).

O Município de Flores da Cunha possui atualmente cerca de 29 mil habitantes, IDHM alto, entre 0,700 e 0,799 e, em 2014, tinha um PIB per capita de $\mathrm{R} \$ 43.124,35$, enquanto em 2015, tinha $69.9 \%$ do seu orçamento proveniente de fontes externas (PNUD, 2017). Em 2015, o salário médio mensal era de 2,7 salários mínimos. A proporção de pessoas ocupadas em relação à população total era de 44,6\%. Considerando domicílios com rendimentos mensais de até meio salário mínimo por pessoa, tinha $20,9 \%$ da população nessas condições.

Com um número de empresas atuantes de 2.154, em 2017, a indústria moveleira do município é uma referência para o Estado do Rio Grande do Sul, empregando uma mão de obra considerável. Além da indústria moveleira, desde 1994, o Município de Flores da Cunha ostenta o título de maior produtor de vinhos do país. Conforme os dados mais recentes disponíveis (do Cadastro Vinícola do RS | Ibravin SEAPPA/RS - Mapa), a produção local em 2016 atinge 120 milhões de litros. O município possui em torno de 200 indústrias vinícolas (desde pequenas cantinas rurais a grandes empresas vinícolas).

\section{Metodologia}

A pesquisa foi desenvolvida através de material bibliográfico, disponíveis na internet e documentação cedida pela indústria moveleira, localizada no Município de Flores da Cunha, em formato de pesquisa qualitativa. 

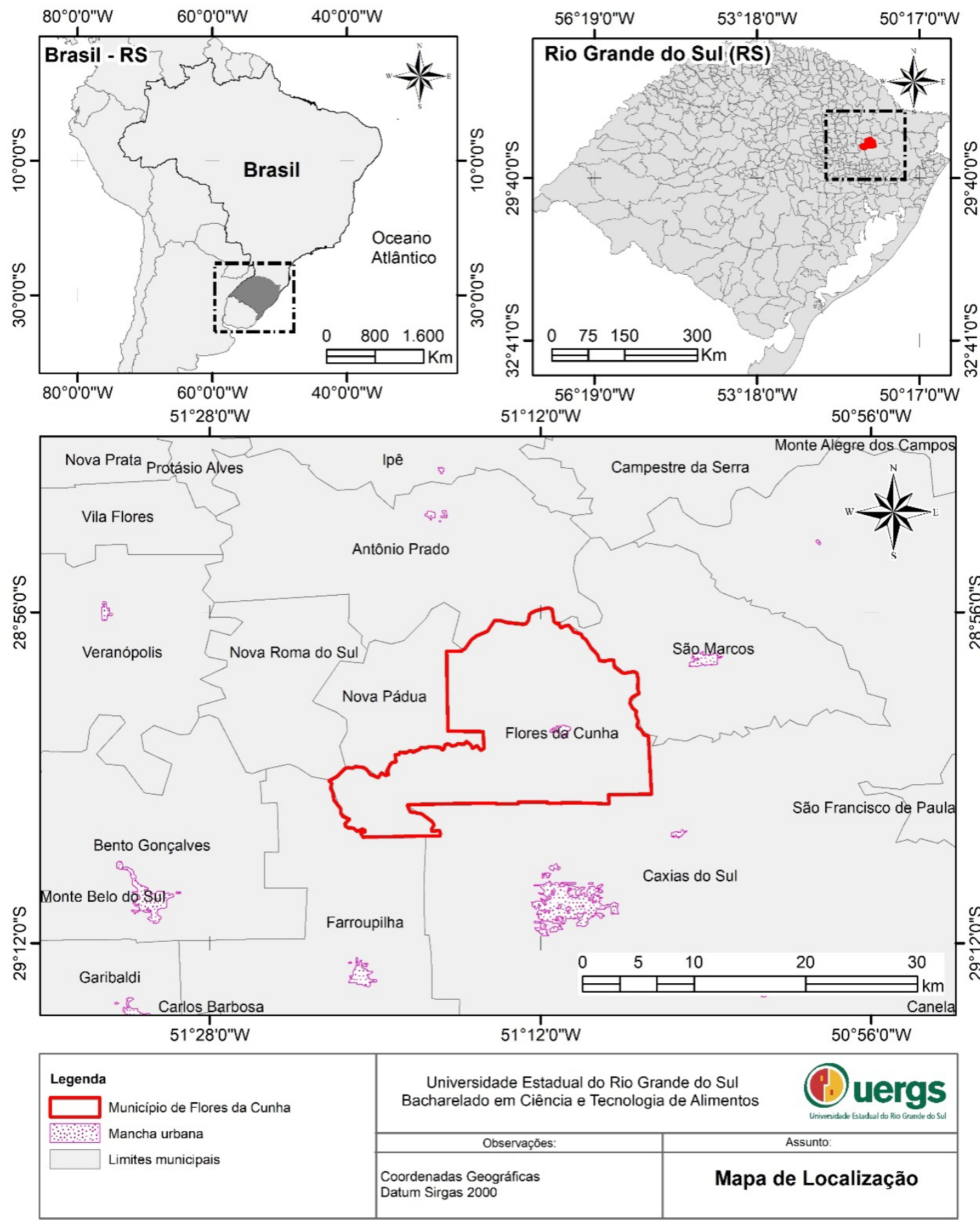

Figura 1. Mapa de localização.

Conforme Oliveira (2007), “a pesquisa qualitativa é um processo de reflexão e análise da realidade através da utilização de métodos e técnicas para compreensão detalhada do objeto de estudo em seu contexto histórico e/ou segundo sua estruturação".
Uma característica marcante da pesquisa qualitativa é seu caráter naturalístico, já que uma vez para estudar o fenômeno relativo às ciências humanas e sociais é necessário que o pesquisador entre em contato direto e prolongado com o ambiente no qual o 
fenômeno está inserido (Martins e Theóphilo, 2007).

Escolheu-se uma indústria do ramo moveleiro, por apresentar grande quantidade de resíduos gerados e consequentemente impactos ambientais. A Unidade analisada, a partir de 2011, iniciou a implantação de um Sistema de Gestão da Qualidade (SGQ), visando a aumentar a satisfação de seus clientes e a melhoria de seus processos para certificação da ISO 9001.

Após o período de preparação de seu SGQ, a empresa já obteve a certificação NBR ISO 9001:2008 (ABNT, 2008), que preparou a empresa para outras certificações, tais como o Forest Stewardship Council (FSC).

A certificação florestal deve garantir que a madeira utilizada em determinado produto é oriunda de um processo produtivo manejado de forma ecologicamente adequada, socialmente justa e economicamente viável, de acordo com os Princípios \& Critérios (P\&C) do FSC.

Com a melhoria contínua de seu Sistema de Gestão da Qualidade e implantação de novas ferramentas e certificações, a empresa, atualmente, migrou do seu atual SGQ para um Sistema de Gestão Integrada, o (SGI), visando a implementação de políticas unificadas e atingimento de metas de forma mais eficiente do que por meio de muitos sistemas de gestão que funcionam de forma independente.

As informações coletadas visualmente, dos processos realizados foram relacionadas com os dados retirados da coleta documental, além de terem sido cruzadas com toda a literatura obtida na pesquisa, para que se pudesse analisar de maneira consistente, a fim de conseguir respostas às indagações, e procurar estabelecer as relações necessárias entre os dados obtidos e as hipóteses formuladas de acordo com os resultados encontrados na pesquisa (Marconi e Lakatos, 2006).

\section{Resultados e discussão}

A classificação de resíduos envolve a identificação do processo ou atividade que lhes deu origem e de seus constituintes e características e a comparação destes constituintes com listagens de resíduos e substâncias cujo impacto à saúde e ao meio ambiente é conhecido. A identificação dos constituintes a serem avaliados na caracterização do resíduo deve ser criteriosa e estabelecida de acordo com as matérias-primas, os insumos e o processo que lhe deu origem (ABNT NBR 10004/2004).

Em trabalhos de campo na indústria foram analisados diversos setores geradores de resíduos e posteriormente foi analisado seu destino e sua periculosidade. Conforme a ABNT NBR 10004:2004 (ABNT, 2004), os resíduos são classificados em: a) resíduos classe I - Perigosos, aqueles que apresentam periculosidade como inflamáveis, corrosivos, tóxicos, patogênicos trazendo riscos à saúde pública e o meio ambiente; b) resíduos classe II - Não perigosos, estes resíduos não se apresentam como inflamáveis, corrosivos, tóxicos, patogênicos, e nem possuem tendência a sofrer uma reação química brusca. Porém isso não significa dizer que não oferecem perigos ao ser humano ou ao meio ambiente. Ainda conforme a classe II, podem ser Resíduos classe II A - Não inertes e Resíduos classe II B - Inertes.

Neste sentido, pode ser observado os resíduos gerados no setor do escritório e o seu destino da indústria localizada no município de Flores da Cunha (Figura 2). 


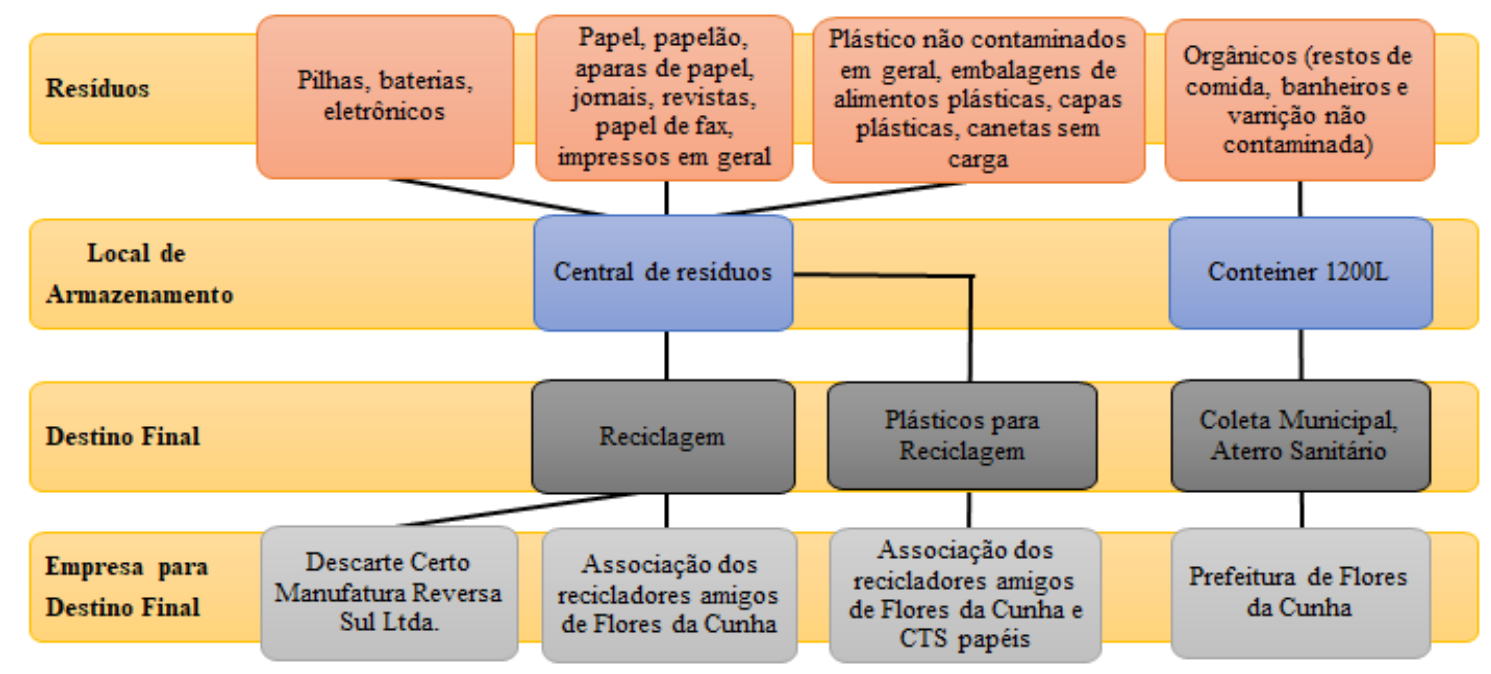

Figura 2. Fluxograma do escritório.

Os resíduos orgânicos desse setor, são direcionados para a coleta municipal e aterro sanitário. Os plásticos não contaminados em geral, embalagens de alimentos plásticas, capas plásticas, canetas sem carga, assim como papel são classificação NBR 10004:2004, em classe II (código A007 e A006) e são encaminhados para a reciclagem.

As pilhas, baterias e eletrônicos, por possuírem periculosidade são encaminhados para uma empresa terceirizada para logística reversa e reciclagem.

A prefeitura de Flores da Cunha tem contratado a Biasotto \& Cia. Ltda, com prestação de serviços de limpeza pública, remoção e beneficiamento de lixo e reciclagem de sucatas metálicas e não metálicas, onde, com licença da FEPAM, construiu uma usina de triagem de lixo com capacidade de 100 toneladas/dia. Opera em vários municípios, na coleta de lixo, tanto orgânico como inorgânico, possui uma frota de caminhões apropriados para a coleta de resíduos e está sempre procurando aprimorar a qualidade de seus serviços.

Em relação ao setor de manutenção da empresa (Figura 3), são gerados resíduos óleos lubrificantes e de corte (Classe I, código F130 e F330), destinado a reciclagem, além de vidros e lâmpadas incandescentes, e lâmpadas fluorescentes e vapor de mercúrio, que são Classe I (código F044), destinados a logística reversa.

A logística reversa é um "instrumento de desenvolvimento econômico e social caracterizado por um conjunto de ações, procedimentos e meios destinados a viabilizar a coleta e a restituição dos resíduos sólidos ao setor empresarial, para reaproveitamento, em seu ciclo ou em outros ciclos produtivos, ou outra destinação final ambientalmente adequada" (MMA, 2014). 


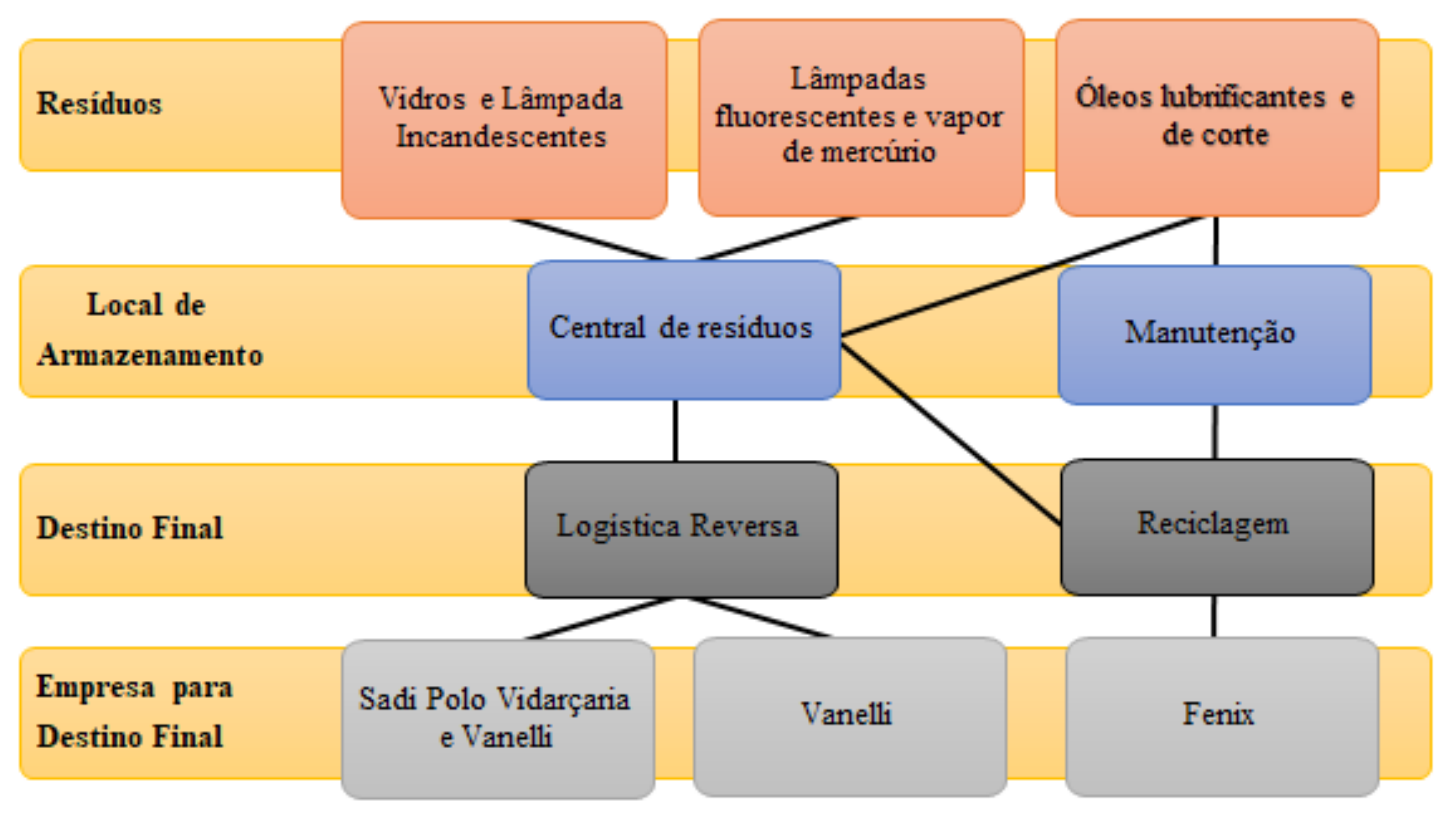

Figura 3. Fluxograma do setor manutenção.

0 Acordo Setorial para implantação do Sistema de Logística Reversa de Lâmpadas Fluorescentes de Vapor de Sódio e Mercúrio e de Luz Mista (SINIR, 2014), foi assinado no dia $27 / 11 / 2014$ e teve seu extrato publicado no D.O.U de 12/03/2015. Seu objetivo é garantir que a destinação final dos resíduos dessas lâmpadas seja feita de forma ambientalmente adequada e em conformidade com a Lei no 12.305/2010, que instituiu a Política Nacional de Resíduos Sólidos (MMA, 2014).

A estofaria é o setor que produz EPIS contaminados, que são Classe I, com código X026, sendo direcionados para coprocessamento. Além dos EPIs, são gerados resíduos têxtis, couro e couro sintético não contaminado e espumas de poliuretano, também direcionados ao coprocessamento (Figura 4).
0 coprocessamento também faz parte do sistema SGA da empresa. O coprocessamento é uma alternativa sustentável e adequada para a destinação desses resíduos, pois representa uma integração segura do material descartado com o processo de fabricação do cimento. É também uma alternativa bastante competitiva em comparação com a disposição dos resíduos em aterros e incineração, caracterizando-se, ao contrário desses, pelo consumo de grandes volumes de resíduos sem geração de novos passivos ambientais.

A produção dos móveis, gera diversos resíduos, que possuem três tipos de destino, a incineração, a reciclagem e o coprocessamento (Figura 5). 


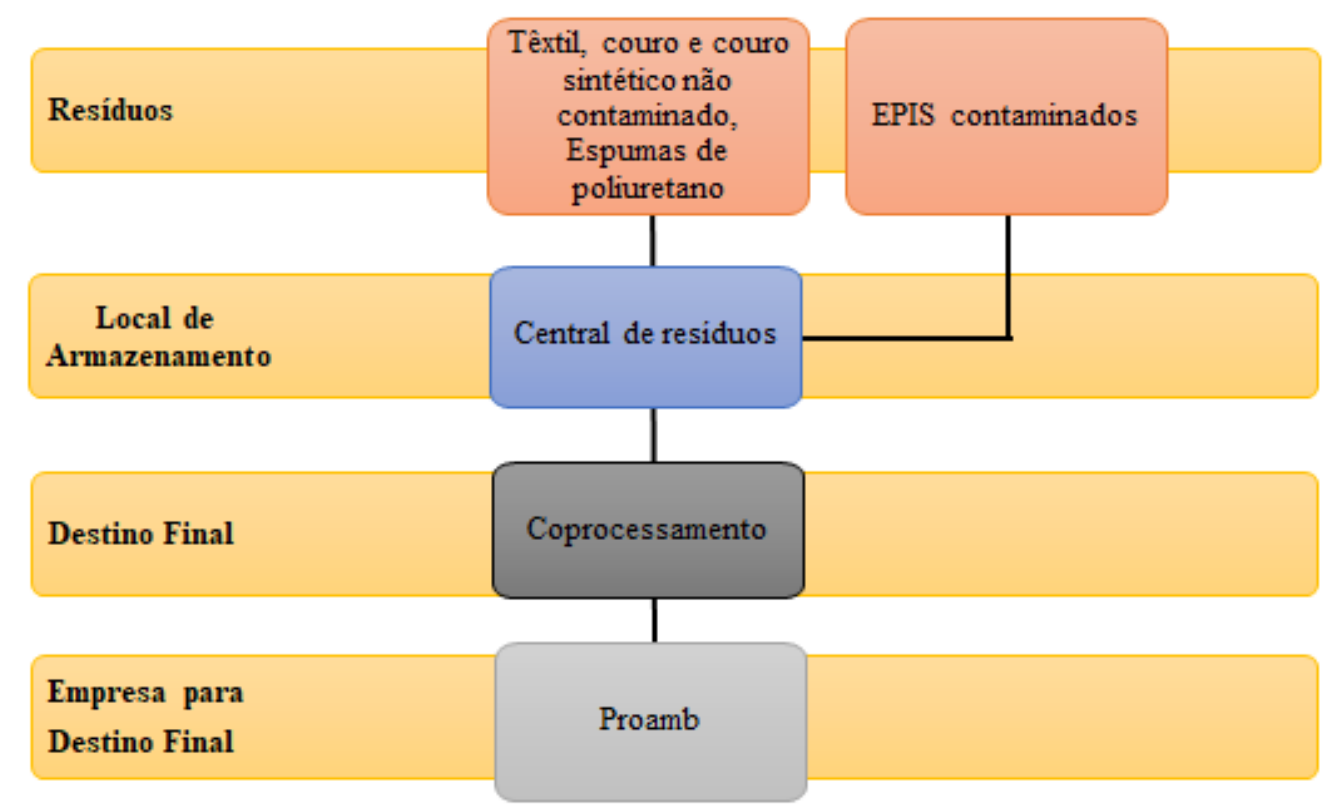

Figura 4. Fluxograma do setor estofaria.

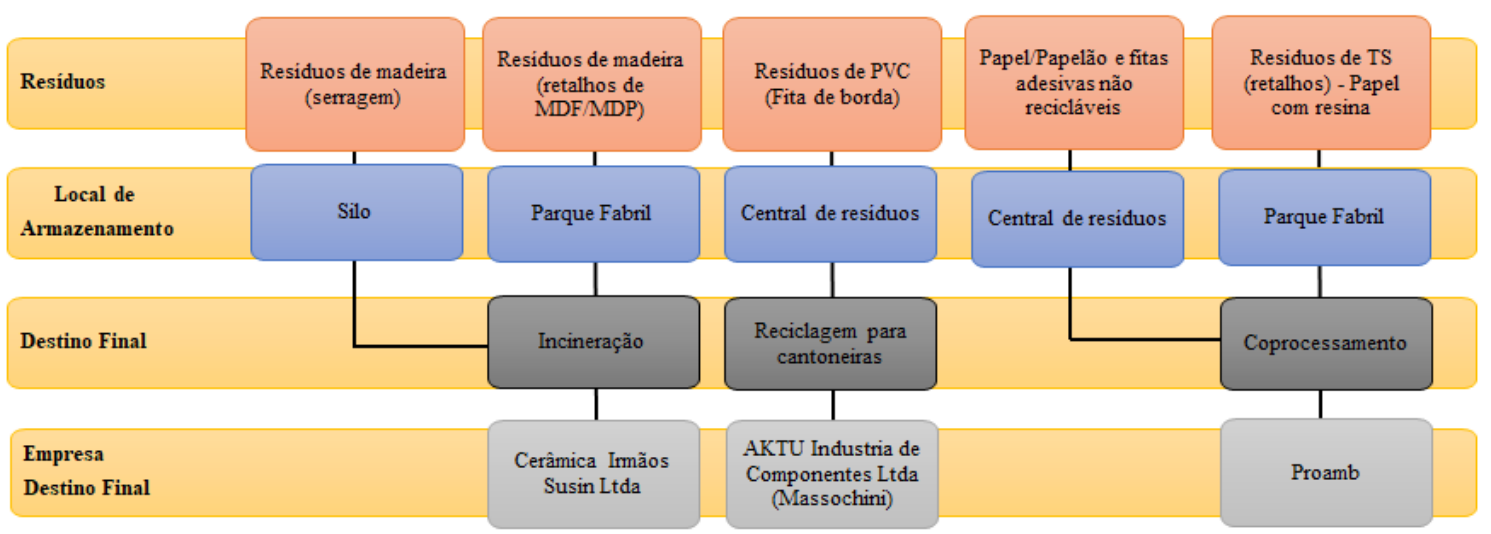

Figura 5. Fluxograma do setor de móveis.

Os resíduos de madeira (serragem), por serem Classe II e código A009, são direcionados a incineração. A incineração tem sido utilizada como um método para processar resíduos desde o início do século XVIII. Durante as últimas décadas ela tem sido amplamente utilizada, estabelecendo tecnologia confiáveis com modernas facilidades. Modernas plantas de incineração estão agora quase todas sendo construídas com aproveitamento energético. A incineração é um processo complementar ao aterramento e aos programas de reciclagem, conhecidos como 3 R's (Reduzir na fonte, Reutilizar e Reciclar) na medida em que estes sejam economicamente viáveis localmente (Calderoni, 1999).

Os resíduos de PVC (fita de borda), por serem Classe II, código F0050, são destinados a reciclagem. 0 papel/Papelão e fitas adesivas não recicláveis (Classe II, código X020) e resíduos de TS (retalhos) - Papel com 
resina (Classe I, código F0050), são destinados ao coprocessamento.

No fluxograma da metalurgia, Figura 6, observamos todos os resíduos da varrição da fábrica contaminado (que contenha restos de produtos químicos ou contaminados), lixas, borra de cola (contaminado), são direcionados ao coprocessamento, por possuírem código
F0050, da classe I, conforme a NBR 10004. Os papel/papelão e plástico contaminados, tinta a pó e tecido contaminado (panos e estopas), contaminados com óleo, graxas, tintas, produtos para ETE (Classe I, código X020), também são destinados ao coprocessamento.

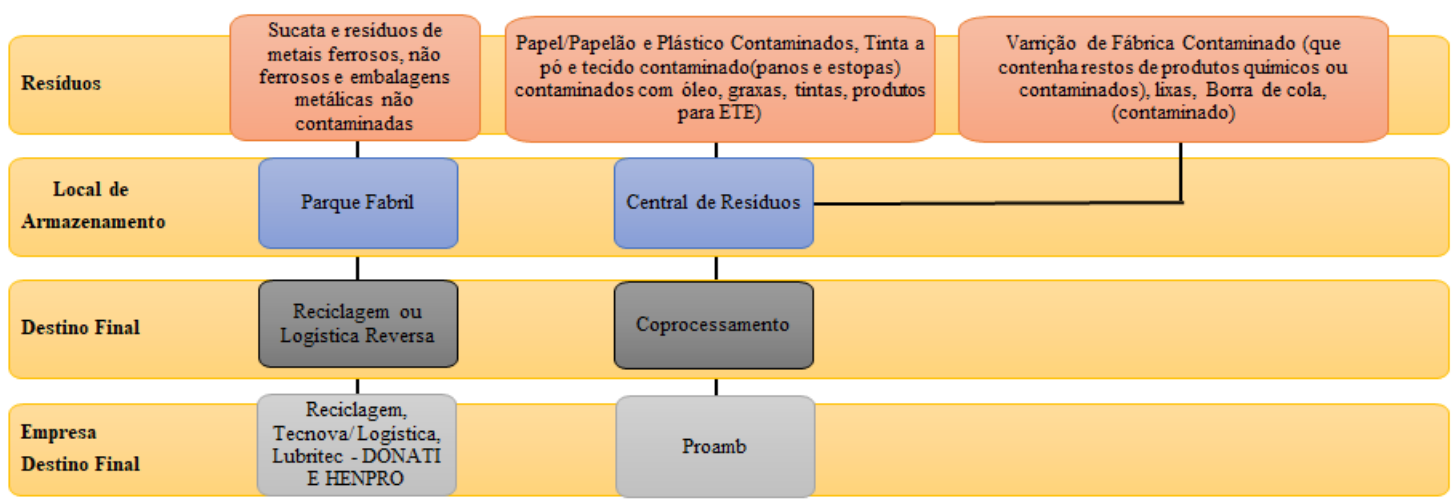

Figura 6. Fluxograma do setor metalúrgica.

A sucata e resíduos de metais ferrosos, não ferrosos e embalagens metálicas não contaminadas, classe II, código A004, são organizados para reciclagem ou logística reversa.

No setor da estação de tratamento de efluente (ETE) (Figura 7), é gerado resíduos provenientes dos efluentes líquidos contaminados. 0 lodo da ETE (Classe I, código F0050/008501) é destinado a aterro sanitário, já as bombonas plásticas contaminadas são descontaminadas.

A Resolução CONAMA $\mathrm{n}^{\underline{0}}$ 275/2001 (Brasil, 2001), estabelece o código de cores para os diferentes tipos de resíduos, a ser adotado na identificação de coletores e transportadores, bem como nas campanhas informativas para a coleta seletiva. Podemos visualizar na Tabela 1.

Verificamos que a geração de resíduos pelos setores é grande, e 100\% são destinados corretamente, conforme a legislação ambiental. A empresa investiu em tratamentos específicos na busca de minimizar impactos no meio ambiente. Assim, destaca-se a importância singular de se implantar sistemas de gestão de resíduos. 


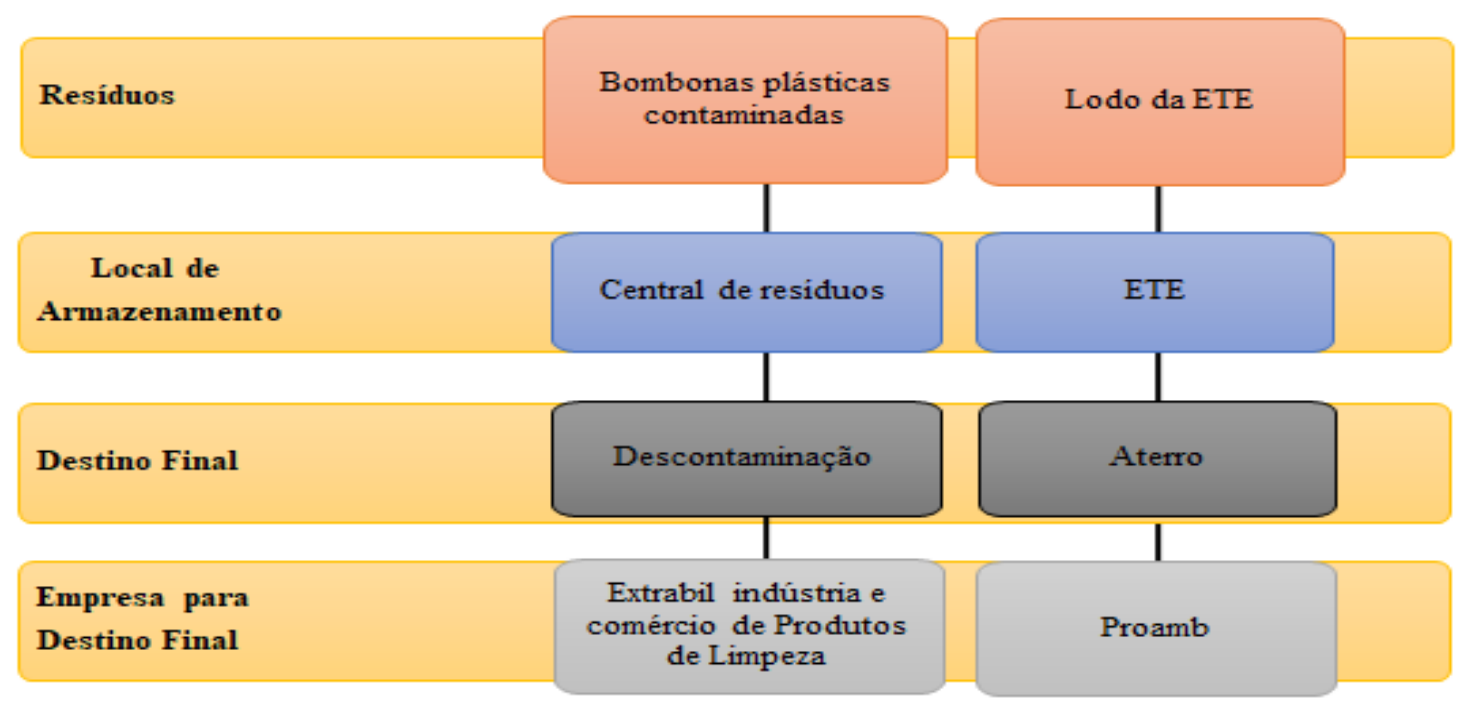

Figura 7. Fluxograma do setor ETE.

Tabela 1. Código de cores em relação aos tipos de resíduos gerados.

\begin{tabular}{|c|c|}
\hline Resíduo & $\begin{array}{l}\text { Coletor conforme } \\
\text { Resolução Conama } \\
275 / 1001\end{array}$ \\
\hline $\begin{array}{l}\text { Plástico não contaminados em geral, embalagens de alimentos plásticas, } \\
\text { capas plásticas, canetas sem carga }\end{array}$ & Vermelho \\
\hline $\begin{array}{l}\text { Varrição de Fábrica Contaminado (que contenha restos de produtos } \\
\text { químicos ou contaminados), lixas, Borra de cola, (contaminado) }\end{array}$ & Cinza \\
\hline Lodo da ETE & Cinza \\
\hline Resíduos de TS (retalhos) - Papel com resina & Cinza \\
\hline Resíduos de PVC (Fita de borda) & Caramelo \\
\hline $\begin{array}{l}\text { Papel, papelão, aparas de papel, jornais, revistas, papel de fax, impressos } \\
\text { em geral }\end{array}$ & Azul Marinho \\
\hline $\begin{array}{l}\text { Papel/Papelão e Plástico Contaminados, Tinta a pó e tecido contaminado } \\
\text { (panos e estopas) contaminados com óleo, graxas, tintas, produtos para } \\
\text { ETE) }\end{array}$ & Cinza \\
\hline Papel/Papelão e fitas adesivas não recicláveis & Azul Céu \\
\hline Resíduos de madeira (retalhos de MDF/MDP) & Preto \\
\hline Resíduos de madeira (serragem) & Preto \\
\hline $\begin{array}{l}\text { Resíduos têxtil, couro e couro sintético não contaminado, Espumas de } \\
\text { poliuretano }\end{array}$ & Azul \\
\hline Lâmpadas fluorescentes e vapor de mercúrio & Laranja \\
\hline Vidros e Lâmpadas incandescentes & Verde \\
\hline $\begin{array}{l}\text { Sucata e resíduos de metais ferrosos, não ferrosos e embalagens metálicas } \\
\text { não contaminadas }\end{array}$ & Amarelo \\
\hline $\begin{array}{l}\text { Resíduos Orgânicos (restos de comida, banheiros e varrição não } \\
\text { contaminada) }\end{array}$ & Marrom \\
\hline EPIS contaminados & Cinza \\
\hline Óleos lubrificantes e de corte & Laranja \\
\hline Pilhas, baterias & Cinza \\
\hline Eletrônicos & Cinza \\
\hline Bombonas plásticas contaminadas & Cinza \\
\hline
\end{tabular}

Fonte: Brasil (2001). 


\section{Conclusão}

O desenvolvimento do presente estudo possibilitou uma análise sobre a correta classificação e caracterização desses resíduos na empresa. Além disso, também permitiu uma análise consistente sobre as etapas dos processos de gerenciamento de resíduos nos seis setores, detalhados em fluxogramas.

É importante afirmar que a empresa avaliada, realiza a destinação final dos resíduos de forma extremamente eficiente, importando-se com a gestão de resíduos, evitando-se o desperdício e a degradação ambiental, e está realizando conforme a Lei no 12.305 , de 2 de agosto de 2010 (BRASIL, 2010) e o Sistema de Gestão Ambiental, assim como a NBR 10004 (ABNT, 2004).

\section{Agradecimentos}

Agradecemos a indústria moveleira, localizada no Município de Flores da Cunha, por todo o apoio e pelos materiais disponibilizados para a pesquisa. E parabenizamos pelo excelente empenho em manter um ambiente sustentável e trazer desenvolvimento econômico e social para a região.

\section{Conflito de interesses}

As autoras declaram não haver conflito de interesses.

\section{Referências}

ABNT - Associação Brasileira de Normas Técnicas. ABNT NBR no 10004:2004 Resíduos sólidos - Classificação. Rio de Janeiro: ABNT, 2004.

ABNT - Associação Brasileira de Normas Técnicas. ISO NBR 9001:2008 - Sistemas de Gestão de Qualidade - Requisitos. Rio de Janeiro: ABNT, 2008.

Brand, M. A.; Hassegawa, M. Determinação da quantidade de resíduos madeiráveis gerados nas indústrias madeireiras em um raio de $150 \mathrm{~km}$ do Município de Otacílio Costa. Lages: Universidade do Planalto Catarinense, 2005.

Calderoni, S. Os bilhões perdidos no lixo. 3. ed. São Paulo: Humanitas, 1999.

Brasil. Conselho Nacional do Meio Ambiente. Resolução CONAMA no 275, de 25 de abril de 2001. Disponível em: <http://www.mma.gov.br/port/conama/legi abre.cfm?codlegi=273>. Acesso em: 01 out. 2017.

Brasil. Conselho Nacional do Meio Ambiente. Resolução CONAMA no 313 , de 29 de outubro de 2002. Disponível em: <http://www.mma.gov.br/port/conama/legi abre.cfm?codlegi=335>. Acesso em: 01 out. 2017.

Brasil. Lei no 12.305, de 2 de agosto de 2010. Institui a Política Nacional de Resíduos Sólidos; altera a Lei $\mathrm{n}$ o 9.605, de 12 de fevereiro de 1998; e dá outras providências. Disponível em: <http://www.planalto.gov. br/ccivil_03/_Ato2007-2010/2010/Lei/ L12305.htm>. Acesso em: 01 out. 2018.

Daian, G.; Ozarska, B. Wood waste management practices and strategies to increase sustainability standards in the Australian wood em furniture manufacturing sector. Journal of Cleaner Production, v. 17, n. 17 , p. 1594-1602, 2009. http://doi.org/ 10.1016/j.jclepro.2009.07.008

Gouveia, N. Resíduos sólidos urbanos: impactos socioambientais e perspectiva de manejo sustentável com inclusão social. Revista Ciência \& Saúde Coletiva, v. 17, n. 6, p. 1503-1510, 2012. http://doi.org/ 10.1590/S1413-81232012000600014

Guéron, A. L.; Garrido, V. Requisitos ambientais, acesso a mercados e competitividade na indústria de madeira e móveis do Brasil. Rio de Janeiro: Inmetro, 2004. Disponível em: <http://www.inmetro. gov.br/producaointelectual/obras_intelectua is/125_obraIntelectual.pdf>. Acesso em: 01 out. 2017.

IEMI - Instituto de Estudos e Marketing Industrial. Brasil Móveis 2015, v. 10, n. 10, 2015.

Lima, E. G. Diagnóstico ambiental de empresas de móveis em madeira situadas no polo moveleiro de Arapongas-PR. Curitiba: Universidade Federal do Paraná, 2005. (Dissertação de mestrado). 
Marconi, M. A.; Lakatos, E. M. Técnicas de Pesquisa. 4. ed. São Paulo: Atlas, 2006.

Martins, G. A.; Theóphilo, C. R. Metodologia da investigação científica para Ciências Sociais Aplicadas. São Paulo: Atlas, 2007.

MMA - Ministério do Meio Ambiente. Acordo setorial de lâmpadas fluorescentes de vapor de sódio e mercúrio e de luz mista. Brasília: MMA/SINIR, 2015.

Nahuz, M. A. R. Uso racional de produtos florestais: tendências e perspectivas. Revista da Madeira, n. 60, 2001. Disponível em: <http://www.remade.com.br/br/revistadam adeira_materia.php?num $=53 \&$ subject=Uso $>$. Acesso em: 01 out. 2017.

Oliveira, M. M. Como fazer pesquisa qualitativa. Petrópolis: Vozes, 2007.

PNUD - Programa das Nações Unidas para o Desenvolvimento. Atlas do Desenvolvimento Humano. Disponível em: <http://www.atlasbrasil.org.br/2013/pt/per fil_m/flores-da-cunha_rs $>$. Acesso em: 01 out. 2017.
Schneider, V. E.; Hillig, E.; Bertotto Filho, L. A.; Rizzon, M. R. Geração de resíduos de madeira e derivados no Polo Moveleiro da Serra Gaúcha: diagnóstico e indicativos para o gerenciamento ambiental na indústria moveleira. Anais do XI Simpósio LusoBrasileiro de Engenharia Sanitária e Ambiental, Natal, 2004.

SINIR - Sistema Nacional de Informações sobre a Gestão de Resíduos Sólidos. MMA Ministério do Meio Ambiente. Acordo Setorial de Lâmpadas Fluorescentes de Vapor de Sódio e Mercúrio e de Luz Mista. Disponível em: <http://www.sinir.gov.br/ web/guest/acordo-setorial-de-lampadasfluorescentes-de-vapor-de-sodio-e-mercurioe-de-luz-mista>. Acesso em: 01 out. 2018.

Wright, R. Environmental Science: Toward a sustainable future. 9. ed. Londres: Prentice Hall, 2004. 